\title{
Las páginas culturales de los diarios como puente de comunicación con el lector
}

\author{
Margarita Pérez de Eulate Vargas \\ Doctora en Comunicación Pública por la Universidad de Navarra y periodista
}

Es evidente que la prensa juega un papel importante en el engranaje cultural de nuestro mundo, ya que además de contribuir a la formación de la opinión pública, vierte sobre los lectores noticias de toda índole que pueden influir en sus decisiones y negocios personales.

La información cultural inserta en los periódicos contribuye de modo destacado a una mayor socialización del público lector y a una elevación del nivel de alfabetización. De las páginas culturales nacen el diálogo y la controversia ideológica que posibilitan el pluralismo y el encuentro con la verdad. Desde ellas también se puede luchar contra la pasividad y convertir la cultura amenazada en algo vivo y eficaz.

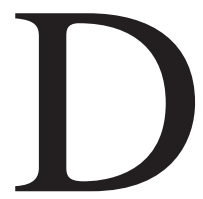

urante este último siglo hemos sido testigos de la revalorización del género crítico debido, en gran parte, a los profundos cambios experimentados por la creación artística que, al ser tan cambian te, ha puesto en crisis todo el sistema valorativo y de enjuiciamiento de épocas anteriores. Los viejos cánones utilizados ya no sirven, al no responder al nuevo concepto de crítica de arte.

Esta situación ha posibilitado, por un lado, el desarrollo de la crítica de artes plásticas como búsqueda de una respuesta clara ante los interrogantes que plantean estas nuevas creaciones.

Por otro lado, es evidente que cada vez se hace más necesario el ejercicio de una crítica informativa, formativa, orientadora y valorativa, ya que no cabe duda de que han sido los críticos, en general, y los de artes plásticas, en particular, los que han acercado el mundo de la expresión creadora al gran público, cada día más consciente de la importancia de complementar su formación con rasgos transcendentes sobre los que poder reflexionar. 
A este respecto Anderson Imbert, en su libro Métodos de crítica literaria, publicado en Madrid a comienzos de la década de los setenta, recoge una anécdota que me parece ilustrativa.

Dicen -escribe Imbert- que Sócrates, en su Apología, narró cómo para medir su propia sapiencia fue a hablar con los poetas.

«Les mostre -cuenta el filósofo- los pasajes más elaborados de sus propios escritos y les pregunté qué significaban confiando que me enseñarían algo. ¿Querreís creerme? Me da vergüenza el decirlo, pero creo que cualquiera de nosotros podría explicar esos poemas mejor que como lo hicieron sus mismos autores. Entonces me di cuenta de que los poetas escriben su poesía, no con la conciencia de un sabio, sino con la inspiración de un genio. Son como esos adivinos e iluminados que expresan hermosas cosas, pero sin comprender su pleno sentido» 1 .

Estas palabras quizá pueden ser también aplicadas a la crítica, ya que quienes la ejercen, tomando como punto de referencia la obra salida de las manos de los artistas, dan vida a una nueva creación que enriquece y contribuye al desarrollo de la primera descubriendo, incluso al propio creador, aspectos que permanecían ocultos en ellas.

En la actualidad y dentro del ámbito periodístico español, la discusión en torno a la crítica de arte se ha convertido casi en un tópico. Las opiniones son tan variadas y contradictorias que la figura del crítico comienza a desdibujarse, debido al escaso conocimiento que se posee del ejercicio de sus funciones.

En opinión de Muñoz Ibáñez, si algo puede definir el pensamiento crítico de nuestra época es su integración en el debate filosófico y cultural planteado. Pocas veces en el siglo de las vanguardias -matiza- se ha producido desde la teoría un cúmulo de reflexiones tan abiertas como ahora, pero tampoco nunca como en este momento, el crítico moderno ha sentido la duda tan próxima hacia su determinación intelectual. Hemos perdido la seguridad -concluye- al balancearse hacia una dirección poco esperada las estructuras sobre las que hemos asentado nuestras reflexiones artísticas ${ }^{2}$.

\footnotetext{
IMBERT, Anderson: Métodos de crítica literaria, Edt. Revista de Occidente, Madrid, 1969, p. 43.

MUÑOZ IBAÑEZ, Manuel : «Estudio sociológico sobre la recepción ciudadana de la labor de la crítica de arte», en El umbral de los 90. Reflexiones sobre la crítica de arte, Edt. Consejería de Cultura, Educación y Ciencia de la Generalitat valenciana, Valencia, 1990, pp. 147-164.
} 
Ante situaciones como la planteada por Muñoz Ibáñez cabría preguntarse: ¿Sirve realmente la crítica -como afirma Antonio Manuel Campoy- para guiar los gustos estéticos del público? ¿Cual es su influencia, si es que tiene alguna, en la formación de la opinión pública? ¿Por qué no dejar al artista crear un nuevo mundo sin que sea turbado por el clamor estridente de la crítica? ¿Por qué escribir más sobre arte? ¿No son ya -como se pregunta Renè Huyghe- demasiados los comentarios, demasiadas las explicaciones acerca de lo que simplemente debería mirarse, de lo que se creó para ser contemplado? ¿Por qué los que no pueden crear se encargan de juzgar a los que crean? ¿Qué autoridad tienen para ello?

Estas preguntas no son nuevas, aunque sus respuestas sean siempre diversas al permanecer subordinadas al contexto socio-cultural y artístico de la época, a los medios de comunicación mediante los que se difunde y a las personas que firman lo escrito.

Estoy de acuerdo con Wilde cuando afirma que una época sin crítica es una época en la que el arte permanece inmóvil, hierático, y de que en ningún momento fue tan necesaria su presencia como ahora, pues es la misma crítica -opina el autor parafraseando a Arnold- la que crea la atmósfera intelectual del mundo, la que hace del espíritu un instrumento afinado y la que posibilita -en definitiva- la cultura intelectual. Es ella -en una palabrala que nos hace cosmopolitas ${ }^{3}$.

Ante la imposibilidad de abarcar un tema tan complejo en toda su amplitud y profundidad nos ceñiremos al ámbito de la prensa escrita en nuestro país y de modo especial a las secciones culturales que acogen este controvertido género periodístico.

Si como afirma Tiján el fin de un periódico es informar sobre los hechos y sucesos más importantes que se producen en todo el mundo, y en cualquier ámbito del conocimiento humano, también la vida cultural tiene derecho a ser representada y reseñada en la prensa diaria.

\footnotetext{
Creo que es interesante transcribir la definición que aporta Oscar Wilde sobre la función crítica en cualquiera de sus modalidades. «La crítica -escribe- es fundamentalmente una creación dentro de otra creación, es el relato de un alma, y por tanto resulta más fascinante que la historia ya que no se ocupa más que de sí misma, tiene más encantos que la filosofía, porque su tema es concreto y no abstracto, real y no vago. Además -continúaes la única forma civilizada de autobiografía, porque se ocupa no de los acontecimientos sino de los pensamientos de la vida de un ser; no de las contingencias de la vida física, sino de las pasiones imaginativas y de los estados superiores de la inteligencia». (WILDE, Oscar: «El crítico artista», en Ensayos/Artículos, Edc. Orbis, Madrid, 1986, pp. 45-46).
} 
De hecho no existe ningún periódico que no posea información cultural, aunque sea entremezclada con otras informaciones y novedades del día.

Sin lugar a dudas, y aquí centraremos nuestra atención, la prensa juega un papel importante dentro del engranaje cultural de nuestro mundo. No sólo porqué contribuye a la formación de la opinión pública, sino porque vierte día tras día sobre los lectores noticias de toda índole, aportando además de la calidad de sus datos, una valoración y unos argumentos que llegan a influir en su formación.

De este modo, la información de la vida cultural tiene como receptores a la gran masa de público que quiere, según argumenta el autor citado, noticias vagas e imprecisas de cuanto pasa en el ámbito de la cultura. De este modo, tienen cabida en este espacio tanto las gacetillas como las entrevistas, tanto las crónicas como los reportajes sobre hechos recientes ocurridos en el mundo de las letras, del arte o del espectáculo ${ }^{4}$.

Un papel destacado dentro de este amplio espectro cultural, dejando aparte los suplementos, es el representado en las páginas que los periódicos dedican expresamente a la misión formadora y educadora, es decir el de las páginas culturales. Estas, al ser leídas generalmente por un tipo de lector medio, aunque se supone que más cultivado, necesitan «algo» más que la escueta información. Es conveniente que posean cierto espíritu crítico, comentarios interpretativos y esclarecedores, seriedad y ponderación de los valores analizados, además de un diseño atractivo y diferenciador.

Generalmente, estas secciones suelen distinguirse de otras del mismo periódico por la mayor cantidad de textos que los colaboradores escriben fuera de la redacción, y que a su vez pueden ser eventuales, habituales o fijos, si los analizamos desde el punto de vista del ritmo de sus colaboraciones, o espontáneas, si lo hacemos desde el punto de vista de la organización del trabajo.

Una sección cultural bien dirigida puede caracterizarse, entre otros aspectos además de los ya citados, por la inclusión de una gran variedad de géneros periodísticos y literarios entre los que cabría destacar: los artículos, los ensayos, las glosas, los editoriales, las crónicas, los reportajes, las cartas, las reseñas y las críticas.

\footnotetext{
TIJAN, P: «La vida cultural en la prensa», en Las secciones de la información de actualidad, Edt. Gómez, Instituto de Periodismo de la Universidad de Navarra, Pamplona, pp. 109-110.
} 
De este modo, toda acción comunicativa de la cultura en la prensa escrita tendría que desbordar los límites mismos de la información para constituirse en creación cultural.

En opinión de Luisa Santamaría esta creación cultural debería asumir el riesgo de ser «un auténtico diálogo con la cultura y también con la propia producción cultural», que en estos momentos se ciñe, casi exclusivamente, a la información, a la creación artística y a las críticas de arte, abarcando estas últimas tanto a la literatura como a las artes plásticas, al teatro, a la música y al cine 5 .

Pero, el mejor criterio de que disponemos en la actualidad para valorar el contenido de una página cultural, es la consideración de servicio que presta de acuerdo con las necesidades culturales del lector. Esta afirmación lleva consigo, por su parte, un doble peligro ya que puede culturizarse lo social o bien sociologizarse de manera irremediable lo cultural, pues al suponerse que el lector tiene un nivel cultural medio no se exige del informador ningún tipo de especialización 6 .

A este respecto, podemos decir con Tubau que, a grandes rasgos, en España, nos encontramos, en lo que a periodismo cultural se refiere, ante una enorme carencia de informadores especializados ${ }^{7}$. Estos quedan suplidos por otros informadores faltos de una formación cultural suficiente, o por especialistas que manejan mal la técnica informativa.

Generalmente, el tipo de páginas de las que hablamos, como escribimos anteriormente, son fáciles de reconocer. En primer lugar porque poseen un aspecto exterior más armonioso, ordenado y equilibrado que el de otras secciones, debido en parte a la menor inclusión publicitaria que facilita el trabajo del diseñador para conseguir el deseado equilibrio entre las superficies ocupadas por el texto y las ocupadas por las ilustraciones. En segundo lugar se distinguen por los titulares, que suelen ser de mayor tamaño que los del resto del periódico, y en último lugar se caracterizan por la brillantez del léxico empleado, rico en metáforas y licencias léxicas.

De estas páginas nacen el diálogo y la controversia ideológica que posibilitará el pluralismo y el encuentro con la verdad. Desde ellas también

\footnotetext{
SANTAMARIA, Luisa: El comentario periodístico. Los géneros persuasivos, Edt. Paraninfo, Madrid, 1990, p. 137.

6 Opt. cit. GARCIA, Mario: Diseño y remodelación de periódicos, Edt. Eunsa, Navarra, 1984, p. 233.

7 TUBAU, Iván: Teoría y práctica del periodismo cultural, Edc. A.T.E., Barcelona, 1982. p. 36.
} 
se puede luchar contra la pasividad y convertir la cultura amenazada en algo vivo y eficaz.

A veces, y esto ocurre cada vez con más frecuencia, son los propios directores de los periódicos los que consideran estas secciones como las menos productivas. Por esta razón les asignan menos recursos y, si hace falta ampliar alguna noticia de otra índole, se hace recortando el espacio concedido a las páginas culturales. En consecuencia, y al ser económicamente débiles, están en constante lucha por su espacio vital. En palabras de Tiján, la posibilidad de desaparecer en cualquier momento les hace estar en un continuo dinamismo creador.

A pesar de todo, las secciones culturales están alcanzando en nuestro país una gran importancia en el ámbito periodístico debido, en gran parte, a su aceptación y valoración por parte del público lector. Así, además de su inclusión entre el resto de los sucesos informativos del día, han conseguido un espacio fijo dentro de la estructuración del periódico y un cuidadoso diseño. Las numerosas cartas recibidas en los medios pone de manifiesto el eco y la influencia que poseen las críticas, los comentarios y las reseñas insertas en ellas.

Sin embargo, la gran diversidad metodológica de las críticas publicadas en estas páginas impide que esta sección sea tan homogénea como otras, en cuanto a lo que a estructuración se refiere. Esto se debe, en cierta medida, a la gran riqueza y variedad que posee el género crítico y literario.

Hasta aquí unas pinceladas teóricas sobre la importancia de la información cultural en las páginas de los diarios y de la crítica de arte, fundamentalmente como género argumentativo de opinión.

La realidad periodística española a este respecto vuelve a poner de manifiesto la consabida separación que existe entre la teoría y la práctica. La mayoría de los diarios que leemos apenas prestan atención a la difusión cultural, trasladando estas informaciones a los suplementos dominicales, a no ser que se trate de un hecho que reúna a personalidades relevantes. Es el ejemplo de Arco' 98, de un concierto en el Palau de la Música, del estreno de una obra teatral que presidan los reyes de España, de la presentación de un libro apadrinado por un político o de hechos semejantes.

En estas situaciones citadas, generalmente, brilla más lo accesorio que rodea al acontecimiento en cuestión que el propio contenido del evento, aunque la tendencia es hacia una leve mejoría.

Así, y a pesar de que la inclusión de páginas culturales en nuestros diarios es escasa, cada vez se está logrando una mayor aceptación entre los 
lectores por su cuidadoso diseño y su especialización. De todos modos, y teniendo en cuenta que son un puente de comunicación importante con el lector interesado en las realidades culturales de nuestro mundo deberían alcanzar una mayor trascendencia y realidad en los medios de comunicación, encargándose de su elaboración periodistas especializados en las cuestiones culturales.

El camino para lograrlo ha empezado ya a dibujarse, aunque tendrá que pasar algún tiempo para que esta aspiración cultural-comunicativa sea una realidad en los mass media de nuestro país. 